\title{
Uma breve comparação entre os mercados de trabalho do setor público e privado
}

Nelson Marconi

Revista do

Serviço

Público

Ano 48

Número 1

Jan-Mar 1997

\section{Apresentação}

Este trabalho discute alguns aspectos do mercado de trabalho do setor público, buscando sempre que possível estabelecer correlações e comparações com o mercado de trabalho do setor privado, de forma a ressaltar eventuais distorções entre ambos, e detalhando as características observadas na administração pública federal no tocante aos servidores civis do Poder Executivo. Na primeira parte, serão confrontadas as características e a evolução do emprego em ambos os mercados; na segunda, as relativas ao perfil e qualificação dos trabalhadores, considerando a sua relação com as atribuições desempenhadas e, finalmente, as intrínsecas aos salários. Os dados comparativos entre os dois mercados são geralmente oriundos das mesmas fontes e quando isto não ocorre, em função da indisponibilidade de informações nas pesquisas utilizadas, atentou-se para a necessidade de torná-los confrontáveis.

\section{A evolução e as características do emprego}

A participação do emprego público no emprego total da economia é relativamente estável e, ao que tudo indica, contracíclica, isto é, há um crescimento da mesma (ainda que modesto) quando o nível de atividade se reduz, porque o emprego público é menos sensível, no curto prazo, às oscilações das taxas de crescimento

Nelson Marconi é mestre e doutorando em economia pela FGV/SP e diretor do Departamento de Carreiras e Remuneração da Secretaria de Recursos Humanos do MARE 
econômico (vide tabela 1). Dito de outra forma, a elasticidade da oferta de serviços públicos em relação ao nível de atividade é bastante reduzida.

Tabela 1: Participação da adm. pública na composição setorial da ocupação nas regiões metropolitanas*

Média no período $(\mathrm{em} \%)$

\begin{tabular}{cccccc}
\hline 1991 & 1992 & 1993 & 1994 & 1995 & jan/jun 96 \\
\hline 9,7 & 10,1 & 10,1 & 9,9 & 9,6 & 9,9 \\
\hline
\end{tabular}

Fonte: PME - IBGE.

* São Paulo, Rio de Janeiro, Belém, Belo Horizonte, Recife e Salvador.

Enquanto o nível de emprego no setor privado cai nos períodos de desaquecimento, o do setor público não se altera, resultando numa maior participação deste último no mercado de trabalho. Neste sentido, o emprego público contribui para amortecer os efeitos da recessão sobre a demanda por mão-de-obra. O comportamento da taxa de rotatividade na administração pública e nos serviços industriais de utilidade pública (ofertados basicamente por estatais) confirma a estabilidade muito maior do emprego nestes setores (vide tabela 2).

Tabela 2: Taxa de rotatividade por setor de atividade (em \%)

\begin{tabular}{lcccccc}
\hline & 1991 & 1992 & 1993 & 1994 & 1995 & jan/mar 96 \\
\hline Ext. Mineral & 2,3 & 1,7 & 1,8 & 1,8 & 2,1 & 2,0 \\
Ind. Transformação & 2,9 & 2,3 & 2,7 & 2,9 & 3,2 & 2,9 \\
Serv. Ind. Util. Pública & 0,6 & 0,6 & 0,6 & 0,8 & 0,9 & 1,2 \\
Constr. Civil & 6,5 & 4,8 & 5,2 & 5,2 & 5,4 & 4,9 \\
Comércio & 3,7 & 3,0 & 3,5 & 3,5 & 3,8 & 3,5 \\
Serviços & 2,9 & 2,3 & 2,5 & 2,7 & 3,0 & 2,9 \\
Administração Pública & 0,6 & 0,2 & 0,3 & 0,3 & 0,4 & 0,4 \\
Agropecuária & 3,0 & 2,5 & 2,8 & 2,9 & 3,6 & 3,6 \\
Outros & 2,0 & 1,9 & 2,0 & 2,1 & 2,2 & 0,9 \\
\hline
\end{tabular}

Fonte: Ministério do Trabalho (Boletim Mercado de Trabalho do Ipea e do próprio ministério).

Ao longo da última década, a evolução do emprego na administração pública global (que inclui o governo federal, os estaduais e municipais) foi positiva ${ }^{1}$, enquanto a análise 
específica dos dados do Poder Executivo federal no mesmo período mostra uma queda inequívoca no seu número de funcionários (tabela 3). Em função da crise fiscal, os concursos públicos se tornaram escassos e irregulares, fato que associado ao crescimento do número de aposentadorias diminuiu consideravelmente o número de servidores civis ativos no Executivo federal ao longo da década. Nas demais esferas de governo, tal movimento não se observa, porque apenas recentemente os estados e municípios sofreram os impactos maiores de tal crise.

Tabela 3: Índice da evolução do nível de emprego

\begin{tabular}{lrcc}
\hline & Total (1) & Adm. públ. (2) & Exec. federal (3) \\
\hline & & & \\
1991 & 100,0 & 100,0 & 100,0 \\
1992 & 99,7 & 103,7 & 103,8 \\
1993 & 101,0 & 104,8 & 99,1 \\
1994 & 103,7 & 106,0 & 97,4 \\
1995 & 106,1 & 105,0 & 96,4 \\
jan/jun/96 & 107,2 & 109,5 & 93,4 \\
\hline
\end{tabular}

Fonte: Pesquisa Mensal de Emprego - IBGE (Boletim Mercado de Trabalho do Ipea e Ministério do Trabalho) e Boletim Estatístico do Min. da Adm. Federal e Reforma do Estado - MARE.

(1) Total - Representa a evolução média do emprego no período considerado nas seis regiões metropolitanas pesquisadas pela PME.

(2) Adm. Públ. - Idem, somente para a administração pública em seus três níveis — federal, estadual e municipal.

(3) Executivo Federal - Representa a evolução do emprego no serviço público federal no tocante aos servidores civis do Executivo (adm. direta, autarquias e fundações).

A tabela 4 reflete a expressiva evolução do número de aposentadorias concedidas ao longo desta década, destacando o ano de 1991 (quando os servidores esperaram a criação do Regime Jurídico Único, e a sua conseqüente transformação em estatutários, para que pudessem passar para a inatividade com vencimentos integrais) e o ano de 1995, quando diversos servidores anteciparam seus pedidos de aposentadoria devido a um receio infundado de alterações nas regras para aqueles que trabalharam ao longo de toda a sua vida profissional sob a égide do regime atual. 


\begin{tabular}{lcc}
\hline & Total anual & Média mensal \\
\hline 1991 & 46.196 & 3.850 \\
1992 & 21.190 & 1.766 \\
1993 & 14.199 & 1.177 \\
1994 & 17.601 & 1.467 \\
1995 & 35.323 & 2.944 \\
1996 & 26.807 & 2.234 \\
\hline
\end{tabular}

Fonte: Boletim Estatístico do MARE.

Em 1991 e 1994 o número refere-se a uma parcela reduzida de servidores do Legislativo e do Judiciário, além destes, e entre 1995 e 1996, refere-se aos civis estatutários do Poder Executivo federal.

A redução na força de trabalho decorrente das aposentadorias termina auxiliando, de forma involuntária, o planejamento do quantitativo de servidores necessário ao desempenho das atribuições do governo federal, uma vez que possibilita a reposição limitada ao número essencial de funcionários. Em 1996, por exemplo, foram contratados 5.756 servidores civis para o Executivo federal, enquanto se aposentaram outros 26.807 (vide tabela 4). Há, inclusive, uma restrição muito forte que deve ser considerada neste planejamento: a queda no número de ativos no Executivo federal não implica redução das despesas, pois, quando o servidor se aposenta, o valor de seus proventos é semelhante ao de seu salário quando em atividade e ele permanece recebendo todos os reajustes concedidos aos servidores ativos. ${ }^{2}$ Logo, o alcance das futuras alterações nas regras de aposentadoria dos servidores certamente influirá no planejamento do quantitativo da força de trabalho no serviço público federal para os próximos anos.

\section{As características pessoais, a qualificação e as carreiras}

O servidor público possui, em média, um nível de escolaridade superior ao do trabalhador no setor privado. A tabela 5 mostra que, enquanto a maioria dos empregados na região metropolitana de São Paulo (onde o acesso à educação, ao que tudo indica, é mais facilitado) não concluiu o $2^{\circ}$ grau, os servidores públicos federais possuem, predominantemente, curso superior completo. Se considerarmos que a informação relativa aos servidores reflete, via de regra, 
o seu nível de estudo quando do ingresso nos quadros de pessoal da União (haja vista que é rara a atualização destes dados cadastrais), esta disparidade pode ser ainda maior.

Tabela 5: Nível de escolaridade

Servidores federais $\mathrm{x}$ trab. setor privado

\begin{tabular}{|c|c|c|}
\hline & Trab. setor privado (1) & Servidores federais(2) \\
\hline Analfabeto & $5 \%$ & $1 \%$ \\
\hline $1^{\circ}$ grau incompleto & $43 \%$ & $14 \%$ \\
\hline $1^{\circ}$ grau completo & $12 \%$ & $9 \%$ \\
\hline $2^{\circ}$ grau incompleto & $7 \%$ & $4 \%$ \\
\hline $2^{\circ}$ grau completo & $16 \%$ & $25 \%$ \\
\hline Superior incompleto & $4 \%$ & $5 \%$ \\
\hline Superior completo & $12 \%$ & $42 \%$ \\
\hline Total & $100 \%$ & $100 \%$ \\
\hline
\end{tabular}

Fonte: Boletim Estatístico do MARE (a partir de dados do SEADE e do próprio ministério)

SEADE: dados de 1995; MARE: dados de fev/97.

(1) Inclui os trabalhadores da região metropolitana de São Paulo.

(2) Servidores civis do Poder Executivo (adm. direta, autarquias e fundações).

Os requisitos de ingresso no serviço público — idade mínima, formação exigida para o exercício das diversas atribuições - e, por outro lado, a precariedade dos postos de trabalho ofertados em diversas áreas no setor privado parecem ser os principais motivadores da situação retratada acima. Os jovens com poucos anos de estudo obtêm empregos de baixa qualidade, muitas vezes no mercado informal, enquanto um indivíduo que aspire concorrer a um cargo no governo federal cujas atribuições sejam extremamente simples deve possuir ao menos o $1^{\circ}$ primeiro grau completo.

Corroborando o argumento acima, observa-se na tabela 6 que há uma concentração de trabalhadores na faixa etária inferior no setor privado, refletindo o ingresso precoce de jovens no mercado de trabalho em atividades pouco qualificadas. No grupo dos servidores ocorre o fenômeno oposto: a freqüência maior ocorre numa faixa muito elevada, entre 41 e 50 anos, e é reduzida no intervalo até 30 anos, demonstrando o preocupante envelhecimento da força de trabalho no serviço público, fruto da já citada irregularidade na realização de concursos nos últimos anos. Para agravar o problema, os funcionários públicos se aposentam relativamente jovens (em média, aos 56 anos), tanto que no intervalo superior a frequiência de trabalhadores no setor privado é maior que no setor público. 


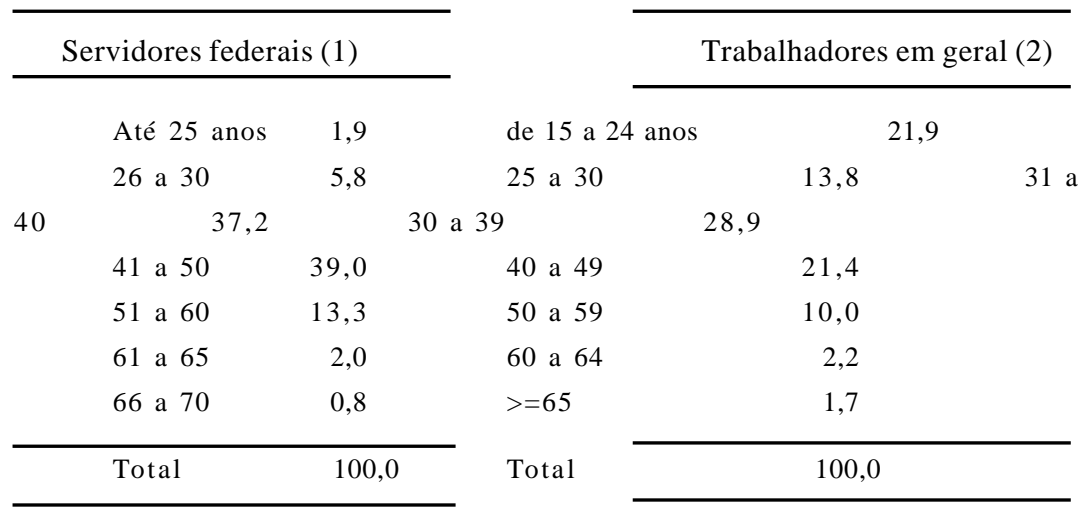

Distribuição \% por sexo

\begin{tabular}{lr}
\hline Servidores federais (1) & \\
\hline Masculino & 55,5 \\
Feminino & 44,5 \\
\hline
\end{tabular}

\begin{tabular}{crr} 
Trabalhadores em geral (2) & \\
\hline $\begin{array}{l}\text { Masculino } \\
\text { Feminino }\end{array}$ & 60,8 & \\
\hline
\end{tabular}

Fonte: Para os servidores federais, Boletim Estatístico do MARE; para os trabalhadores privados, Pesquisa Mensal de Emprego - IBGE (Boletim Mercado de Trabalho do Ipea e Ministério do Trabalho).

(1) Servidores civis do Poder Executivo (adm.direta, autarquias e fundações); posição de agosto/96.

(2) Dados referentes aos trabalhadores de seis regiões metropolitanas - São Paulo, Rio de Janeiro, Belém, Belo

Horizonte, Recife e Salvador; posição média de jan-mar/96.

Não há, entretanto, correspondência estrita entre o nível de escolaridade dos servidores civis do Executivo e o perfil dos cargos ocupados pelos mesmos. Apenas 34\% dos servidores ocupam cargos cujas atribuições exigem formação superior, enquanto a maior parte - $60 \%$ ocupa cargos que exigem $2^{\circ}$ grau para o seu desempenho e $6 \%$ exercem atribuições que demandam somente o $1^{\mathrm{o}}$ grau. ${ }^{3}$ Se considerarmos que a maioria das atividades finalísticas e de apoio dos órgãos são atribuídas, respectivamente, aos ocupantes de cargos que requerem formação superior e de nível médio, pode-se afirmar que há um excesso de funcionários nas áreas de suporte e escassez nas áreas finalísticas dos diversos órgãos.

Como o processo de reforma do Estado levará o governo federal a centrar suas atividades em áreas consideradas finalísticas formulação, fomento e execução de tarefas nas quais exerce o seu poder extroverso - , deduz-se que a atual composição da estrutura de cargos do Executivo é incompatível com o papel que lhe está sendo atribuído na esfera federal. É preciso, portanto, fortalecer o sistema de contratação e de carreiras nas áreas consideradas relevantes sob o ponto de vista da gestão de recursos humanos.

O atual sistema de carreiras da administração pública apresenta diferenciações significativas em relação ao modelo que vem 
sendo adotado no setor privado. Neste último, as empresas vêm dando preferência à contratação de pessoas que possuam um leque maior de conhecimentos, em condições de desempenhar funções mais abrangentes e de se adaptar às necessidades de mobilidade da organização. Na Inglaterra e na França, o sistema é parecido: o funcionário ingressa no serviço público, possui um cargo genérico e pode desempenhar diversas atribuições, em áreas distintas ao longo do tempo, de acordo com as suas habilidades. ${ }^{4}$

$\mathrm{Na}$ administração pública federal, a estrutura é muito mais rígida. Os cargos foram desenhados com atribuições muito específicas, e o servidor que ingressa para desempenhar determinada função não pode ser deslocado para outra, sob pena de os administradores cometerem uma inconstitucionalidade. Muitas vezes, o cargo é também exclusivo do quadro de pessoal de um determinado órgão, o que impede o exercício de seus servidores em outros locais. É fácil perceber que a flexibilização desta estrutura é necessária tanto para aumentar a eficiência da administração como para impedir o inchamento desnecessário de órgãos, resultante da excessiva especialização de cada cargo perante o imenso número de atribuições desempenhadas pelo Estado. A rigidez impede uma proximidade maior com as regras praticadas nas instituições modernas cuja administração possua características eminentemente gerenciais e dificulta a adequação do perfil do servidor ao processo de reestruturação do governo federal.

O sistema atual apresenta também algumas peculiaridades que revelam uma certa distância entre o discurso defendido pela alta burocracia e as suas reivindicações efetivas. Em um de seus recentes artigos, BRESSER PEREIRA (1996: 17-18) discorre sobre o mito das carreiras: “... Mito porque se prega a instauração das carreiras, ao mesmo tempo que, de fato, não se acredita nelas, e se as destrói na prática...".Esta destruição ocorreu porque nos últimos anos foi sensivelmente reduzida a distância entre o salário inicial e final dos diversos cargos e, em decorrência, foi praticamente eliminada a estrutura de evolução temporal, associada ao desempenho e treinamento, típica de uma carreira burocrática, fortemente defendida por uma parcela da alta administração pública.

A redução da amplitude salarial teve início com a adoção de uma estratégia de reivindicação de gratificações específicas pelas carreiras mais fortalecidas que, concedidas a um pequeno número de servidores, não geravam pressões significativas sobre a folha de pagamentos num período em que a contenção de gastos tornou-se fundamental e criavam condições para que os grupos com maior poder de barganha e/ou pertencentes às áreas essenciais de atuação do Estado melhorassem seus salários. ${ }^{5}$ 
De fato, as carreiras mais importantes devem receber uma remuneração diferenciada, mas a forma adotada para o cálculo destas gratificações - cujo valor é praticamente fixo, independentemente da posição do servidor na carreira - mostrou que os funcionários buscaram a máxima aproximação entre o salário inicial e final (ver tabela 7) e, portanto, descartaram uma característica fundamental do sistema de carreiras — a amplitude salarial, sem a qual não há estímulo para o próprio desenvolvimento pessoal. Além disso, tais gratificações, via de regra, estão associadas ao desempenho, mas como a sua participação na remuneração total varia entre 70 e $90 \%$, o processo de avaliação da performance dos servidores torna-se prejudicada, pois oscilações nos seus resultados provocariam variações salariais significativas e indesejáveis. Conseqüentemente, há uma tendência para avaliar continuamente os servidores com a nota máxima.

\section{Tabela 7: Estrutura das carreiras da administração pública federal} Posição de dezembro - 1996

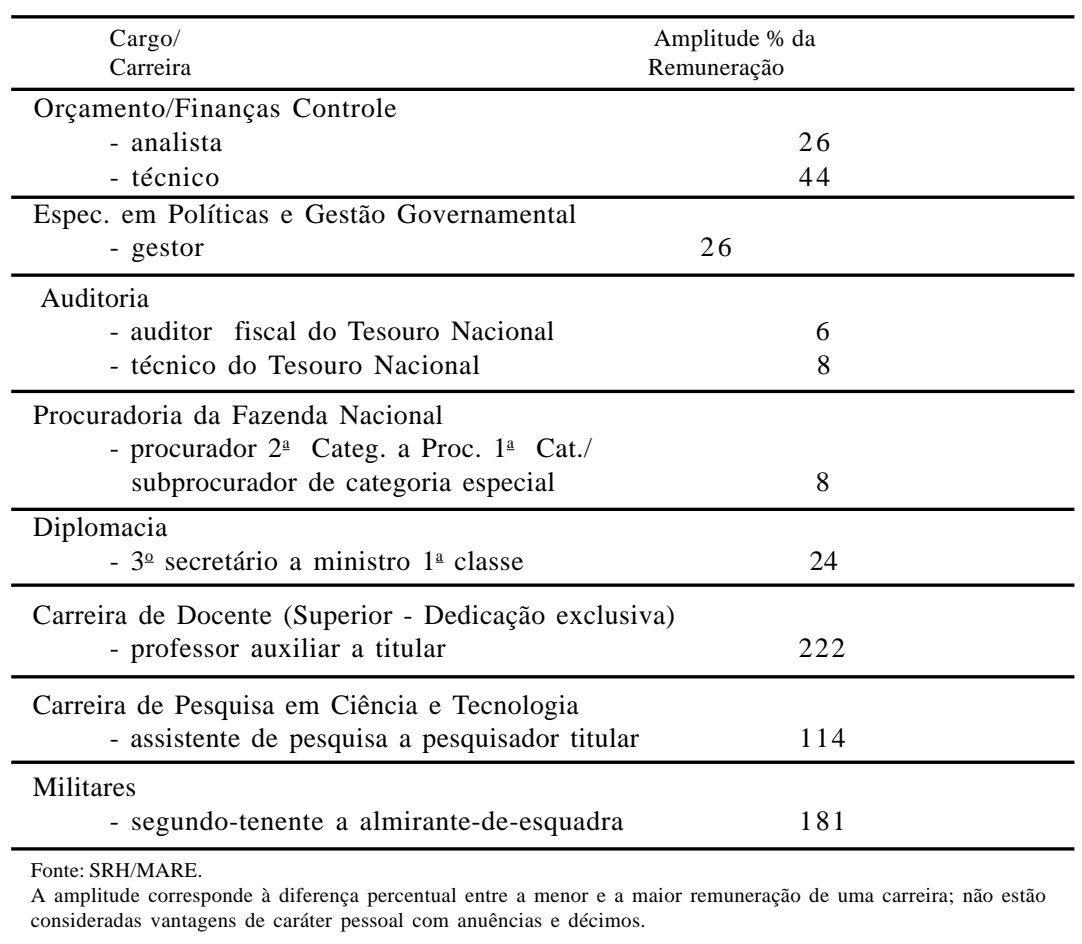

A reduzida amplitude salarial é observada também nas demais esferas de governo, conforme podemos observar na tabela 8, que estabelece uma relação próxima da unidade entre o salário inicial e final na administração pública global. ${ }^{6}$ 
Tabela 8: Relação entre o primeiro salário do admitido e o último desligado

\begin{tabular}{lcccccc}
\hline & 1991 & 1992 & 1993 & 1994 & 1995 & jan/jun 96 \\
\hline $\begin{array}{lcccccc}\text { Ext. mineral } \\
\text { Ind. transformação }\end{array}$ & 0,89 & 0,94 & 0,87 & 0,94 & 0,78 & 0,76 \\
$\begin{array}{l}\text { Serviços industriais } \\
\text { de utilidade pública }\end{array}$ & 0,90 & 0,87 & 0,84 & 0,92 & 0,86 & 0,82 \\
$\begin{array}{l}\text { Constr. civil } \\
\text { Comércio }\end{array}$ & 0,85 & 0,82 & 0,73 & 0,87 & 0,60 & 0,66 \\
\hline Serviços & 1,01 & 0,98 & 0,93 & 0,95 & 0,94 & 0,93 \\
Adm. pública & 0,96 & 0,93 & 0,91 & 0,99 & 0,91 & 0,88 \\
Agropecuária & 0,96 & 0,92 & 0,91 & 0,94 & 0,87 & 0,88 \\
Outros & 1,04 & 1,01 & 1,12 & 1,11 & 0,98 & 0,93 \\
& 0,99 & 0,93 & 0,93 & 1,10 & 0,95 & 0,87 \\
& 0,94 & 0,93 & 0,90 & 0,97 & 0,90 & 0,99
\end{tabular}

Fonte: CAGED/Ministério do Trabalho (Boletim Mercado de Trabalho do Ipea e do próprio ministério).

Em resumo, a discussão acima demonstrou que não há uma correlação direta entre a escolaridade dos servidores, os cargos que ocupam e suas respectivas atribuições, enquanto as carreiras específicas de uma atividade ou órgão (assim como suas gratificações) e a quantidade excessiva de cargos de apoio são incondizentes com o processo de modernização do Estado, o qual deverá levar os servidores a desempenharem uma gama maior de atribuições que exigirão habilidades variadas. Neste sentido, uma reformulação do sistema de carreiras, que o torne compatível com a reforma em curso, associada ao estímulo à capacitação, torna-se fundamental.

\section{A evolução dos salários e a questão fiscal}

O comportamento dos salários no setor público está intimamente associado às restrições de ordem fiscal. Os dados da tabela 9 mostram uma estabilidade bastante razoável na participação dos gastos com pessoal da União em relação à receita disponível (após as transferências) do Tesouro nos últimos anos. Como a evolução dos salários guarda estreita correlação com a dos gastos com pessoal, ${ }^{7}$ pode-se afirmar que as variações das remunerações devem se comportar de forma próxima às observadas para a receita. Da mesma forma, com exceção de 1989 e 1993, os gastos com pessoal mantiveram uma participação relativamente estável nas despesas globais após as transferências, demostrando que ambos oscilam na mesma 
direção, em intensidade bem próxima. Logo, pode-se afirmar que o comportamento dos salários dependerá também das metas de contenção ou expansão dos gastos públicos, mesmo sendo uma despesa relativamente rígida.

\section{Tabela 9: Participação da despesa com pessoal da União}

\begin{tabular}{lcc}
\hline & $\begin{array}{l}\text { Na receita } \\
\text { disponível(1) }\end{array}$ & $\begin{array}{l}\text { Nas despesas } \\
\text { não-vinculadas (2) }\end{array}$ \\
\hline Média 82/85 & $39,1 \%$ & \\
Média 86/88 & $45,5 \%$ & \\
1989 & $46,0 \%$ & $28,4 \%$ \\
1990 & $60,1 \%$ & $47,2 \%$ \\
1991 & $57,9 \%$ & $52,5 \%$ \\
1992 & $57,2 \%$ & $51,5 \%$ \\
1993 & $60,4 \%$ & $42,0 \%$ \\
1994 & $56,2 \%$ & $53,2 \%$ \\
1995 & $62,6 \%$ & $53,7 \%$ \\
1996 & $62,5 \%$ & $51,2 \%$ \\
\hline
\end{tabular}

Fonte: Execução Financeira do Tesouro Nacional.

(1) Receita tributária bruta (-) incentivos fiscais (-) despesas vinculadas; não corresponde ao critério da Lei Camata (2) Total de despesas (-) despesas vinculadas.

À medida que a composição entre gastos com ativos e inativos vem se alterando em favor dos últimos, a partir de 1992, e considerando que as regras atuais de aposentadoria levarão à crescente participação do gasto com inativos na despesa total com pessoal, o grau de liberdade para a implementação de políticas salariais desvinculadas da questão fiscal tende a diminuir. Ao possibilitarem a inversão desta tendência, as mudanças propostas nas reformas administrativa e previdenciária tornam-se fundamentais para a implementação de uma política menos restritiva na área de recursos humanos.

Tabela 10: Composição da despesa com pessoal da União

\begin{tabular}{lcccc}
\hline & Ativos & Inativos & $\begin{array}{c}\text { Benefícios } \\
\text { globais e ajustes }\end{array}$ & $\begin{array}{c}\text { Transferências } \\
\text { intergovern. }\end{array}$ \\
\hline 1987 & $64,0 \%$ & $23,0 \%$ & $7,0 \%$ & $7,0 \%$ \\
1988 & $66,0 \%$ & $24,0 \%$ & $5,0 \%$ & $5,0 \%$ \\
1989 & $66,0 \%$ & $23,0 \%$ & $5,0 \%$ & $6,0 \%$ \\
1990 & $67,0 \%$ & $26,0 \%$ & $0,0 \%$ & $7,0 \%$ \\
1991 & $70,0 \%$ & $24,0 \%$ & $0,0 \%$ & $6,0 \%$ \\
1992 & $67,0 \%$ & $27,0 \%$ & $0,0 \%$ & $6,0 \%$ \\
1993 & $56,0 \%$ & $38,0 \%$ & $0,0 \%$ & $6,0 \%$ \\
1994 & $54,0 \%$ & $41,0 \%$ & $-1,0 \%$ & $6,0 \%$ \\
1995 & $52,0 \%$ & $42,0 \%$ & $0,0 \%$ & $6,0 \%$ \\
1996 & $53,0 \%$ & $42,0 \%$ & $0,0 \%$ & $5,0 \%$ \\
\hline
\end{tabular}

Fonte: Boletim Estatístico do MARE, a partir de dados do Tesouro Nacional.

Algumas características do sistema remuneratório devem ser ressaltadas. A menor amplitude salarial, apesar de prejudicial à estrutura 
das carreiras, exerce um efeito benéfico sobre a distribuição da renda no grupo dos servidores. Existe uma freqüência elevada de funcionários públicos, considerados os três níveis de governo, cuja remuneração se encontra no intervalo entre três e dez salários mínimos, enquanto se computada a totalidade dos trabalhadores a freqüência maior se situa no intervalo entre menos que um e dois salários mínimos. Segundo o Ipea, os $50 \%$ mais pobres se apropriaram de $11,6 \%$ da renda nacional em 1995, enquanto os $20 \%$ mais ricos obtiveram $63,3 \%$ da mesma. ${ }^{8}$ Não foi divulgada análise semelhante para o setor público seguindo os mesmos parâmetros, mas alguns dados disponíveis parecem confirmar que a renda é melhor distribuída no mesmo.

Para traçar tal conclusão, é necessário, inicialmente, explicar que é possível inferir se a renda é concentrada através da relação entre o percentual da massa salarial apropriada pelas pessoas que recebem salários situados, em uma determinada faixa de rendimento, e o percentual relativo à quantidade de pessoas cujos salários se situam nesta mesma faixa. Esta relação é necessariamente crescente à medida que é calculada para as faixas de rendimento superiores, pois, nestas últimas deve existir um número menor de pessoas que se apropriam de uma parcela maior da renda que as situadas nas faixas inferiores (pois os salários são maiores nas faixas mais elevadas).

Quando analisados os dados referentes ao conjunto dos trabalhadores da economia, observa-se que esta relação evolui a taxas bastantes significativas, enquanto os dados relativos ao grupo dos servidores mostram que esta relação cresce de forma menos acentuada (tabela 12). Logo, para o conjunto dos trabalhadores, as pessoas situadas no estrato superior de rendimentos se apropriam de uma parcela maior da renda que os servidores situados em semelhante intervalo salarial. Este é um indício muito forte de que a renda é mais concentrada entre os trabalhadores do setor privado do que entre os do setor público. ${ }^{9}$

Tabela 11: Distribuição \% dos trabalhadores por classe de rendimento - 1995 (em salários mínimos)

\begin{tabular}{lcccc}
\hline & Total & $\begin{array}{c}\text { c/ Carteira } \\
\text { assinada }\end{array}$ & $\begin{array}{c}\text { Estatutários } \\
\text { militares }\end{array}$ & Outros \\
\hline até 1 & 26,4 & 11,3 & 9,2 & 51,8 \\
mais de 1 a 2 & 25,6 & 26,4 & 17,1 & 27,1 \\
mais de 2 a 3 & 15,6 & 20,5 & 15,0 & 9,1 \\
mais de 3 a 5 & 14,5 & 19,4 & 20,1 & 6,2 \\
mais de 5 a 10 & 10,9 & 14,0 & 23,1 & 3,2 \\
mais de 10 a 20 & 4,4 & 5,5 & 10,6 & 1,1 \\
mais de 20 & 1,6 & 2,1 & 4,0 & 0,3 \\
sem rendimento & 0,3 & 0,0 & 0,0 & 0,6 \\
sem declaracão & 0,7 & 0,8 & 0,9 & 0,5 \\
\hline & & & \\
Fonte: PNAD/95 - IBGE. & \multicolumn{4}{l}{} \\
Inclui as pessoas empregadas com 10 anos de idade ou mais no Brasil, à exceção da área rural da Região Norte.
\end{tabular}


Tabela 12: Distribuição dos trabalhadores e da massa salarial por faixa de remuneração

\begin{tabular}{lcccccc}
\hline & Dist.\% dos empregados & \multicolumn{2}{c}{ Dist. \% da massa salarial } & \multicolumn{2}{c}{ Relação massa sal./empreg. } \\
\hline $\begin{array}{l}\text { Em salários } \\
\text { mínimos }\end{array}$ & $\begin{array}{l}\text { Estatutários } \\
\text { e militares }\end{array}$ & $\begin{array}{c}\text { Global } \\
(1)\end{array}$ & $\begin{array}{l}\text { Estatutários } \\
\text { e militares }\end{array}$ & $\begin{array}{c}\text { Global } \\
(1)\end{array}$ & $\begin{array}{c}\text { Estatutários } \\
\text { e militares }\end{array}$ & $\begin{array}{c}\text { Global } \\
(1)\end{array}$ \\
\hline & 9,0 & 26,0 & 1,0 & 4,0 & 0,1 & 0,2 \\
até 1 & 52,0 & 56,0 & 23,0 & 37,0 & 0,4 & 0,7 \\
mais de 1 a 5 & 23,0 & 11,0 & 27,0 & 23,0 & 1,2 & 2,1 \\
mais de 5 a 10 & 11,0 & 4,0 & 24,0 & 18,0 & 2,3 & 4,1 \\
mais de 10 a 20 & 4,0 & 2,0 & 23,0 & 17,0 & 5,8 & 10,6 \\
mais de 20 & & & & & &
\end{tabular}

Fonte: PNAD (1995)

(1) Inclui o total de trabalhadores com 10 anos ou mais, à exceção da área rural da Região Norte.

No Poder Executivo federal, confirma-se a distribuição salarial observada para a administração pública geral: a maior freqüência ocorre na faixa entre seis a nove salários mínimos e não há uma concentração demasiada em nenhuma das faixas.

Tabela 13: Distribuição dos servidores por faixa de remuneração

\begin{tabular}{lr}
\hline Em reais & Dist. $\%$ \\
\hline Até 500 & 11,60 \\
De 501 a 1.500 & 65,10 \\
De 501 a 750 & 18,60 \\
De 751 a 1.000 & 24,80 \\
De 1.001 a 1.250 & 13,80 \\
De 1.251 a 1.500 & 7,90 \\
De 1.501 a 2.500 & 13,30 \\
De 2.501 a 3.500 & 4,20 \\
De 3.501 a 4.500 & 1,80 \\
De 4.501 a 5.500 & 2,20 \\
De 5.501 a 6.500 & 1,10 \\
De 6.501 a 7.500 & 0,30 \\
De 7.501 a 8.500 & 0,20 \\
Acima de 8.500 & 0,10 \\
\hline Total &
\end{tabular}

Fonte: Boletim Estatístico do MARE.

A distribuição foi feita a partir do cálculo do salário médio dos últimos 12 meses até junho/96. Inclui os servidores civis do Executivo.

Os dados também demonstram que, além da renda ser melhor distribuída, o servidor público ganha, em média, um salário superior ao de outros setores da economia. A comparação nas regiões metropolitanas pesquisadas pelo IBGE mostra que o nível salarial dos diversos grupos pesquisados é inferior ao da administração pública; 
as exceções são os dos serviços industriais de utilidade pública, composto basicamente por empresas estatais, e os das empresas extrativas minerais, cuja participação é ínfima nos centros urbanos, sendo a Petrobrás um dos seus maiores representantes.

Tabela 14: Renda média real por setor de atividade nas regiões metropolitanas *

(Adm. pública= 100)

\begin{tabular}{|c|c|c|c|c|c|c|}
\hline & 1991 & 1992 & 1993 & 1994 & 1995 & jan/jun 96 \\
\hline Ext. mineral & 114,2 & 154,5 & 162,0 & 154,7 & 142,0 & 147,1 \\
\hline Ind. transformação & 89,0 & 101,4 & 106,3 & 100,8 & 94,5 & 96,7 \\
\hline \multicolumn{7}{|l|}{ Serv. Ind. } \\
\hline Utilidade Pública & 124,9 & 150,5 & 151,0 & 143,2 & 126,2 & 131,1 \\
\hline Constr. civil & 59,9 & 61,3 & 60,9 & 58,1 & 61,5 & 62,4 \\
\hline Comércio & 66,4 & 67,3 & 71,2 & 73,1 & 72,5 & 75,5 \\
\hline Serviços & 61,2 & 64,6 & 66,6 & 67,7 & 69,6 & 73,3 \\
\hline Adm.pública & 100,0 & 100,0 & 100,0 & 100,0 & 100,0 & 100,0 \\
\hline Agropecuária & 49,2 & 45,4 & 49,1 & 51,6 & 65,4 & 67,0 \\
\hline Outros & 112,0 & 122,7 & 133,9 & 127,4 & 115,9 & 121,7 \\
\hline Média & 86,3 & 96,4 & 100,1 & 97,4 & 94,2 & 97,2 \\
\hline
\end{tabular}

Fonte: PME - IBGE

Os índices correspondem aos valores anuais médios, e se encontram em reais de dezembro/1995

* São Paulo, Rio de Janeiro, Belém, Belo Horizonte, Recife e Salvador.

De fato, as informações da PNAD, mais abrangentes que as restritas às regiões metropolitanas, também indicam que os salários dos servidores estatutários e militares são maiores que os dos demais grupos.

Houve uma sensível melhoria dos salários dos servidores públicos federais nos últimos anos. Em 1995, foi atingido o patamar mais elevado desde o final da década passada, e atualmente a remuneração média pertence num nível bastante superior ao de outros períodos, a despeito de não ter ocorrido nenhum reajuste nos últimos dois anos. Esta recomposição foi fruto dos aumentos reais concedidos em 1993 e 1994, do posterior reajuste linear no início de 1995 e de diversos reajustes setoriais que foram concedidos ao longo do mesmo ano, além, é claro, da própria interrupção do processo inflacionário, pois qualquer reajuste, mesmo que nominalmente elevado, era corroído após poucos meses.

É importante detalhar a discussão em torno da comparação entre o salário médio dos servidores e dos trabalhadores privados, pois se os primeiros possuem mais anos de estudo, é razoável que a sua remuneração também seja mais elevada. Logo, deve-se analisar a relação entre tais salários médios após o controle desta característica. Para tal, foi comparada a remuneração de diversos cargos, se não comuns, com atribuições muito próximas no setor público e 
no privado que, naturalmente, exigem qualificação semelhante para o seu exercício. ${ }^{10}$ Os resultados mostram que o salário médio é mais elevado no setor privado para os cargos que exigem maior qualificação, enquanto é superior no setor público para aqueles com menor qualificação, confirmando o comportamento da distribuição da renda discutido anteriormente. ${ }^{11}$

Tabela 15: Rendimento real no trabalho principal (em salários mínimos)

\begin{tabular}{lcccc}
\hline & Total & $\begin{array}{c}\text { c/ Carteira } \\
\text { assinada }\end{array}$ & $\begin{array}{c}\text { Estatutários } \\
\text { e militares }\end{array}$ & Outros \\
\hline 1985 & 3,1 & 4,1 & & \\
1986 & 3,9 & 5,0 & & \\
1987 & 3,2 & 4,2 & & \\
1988 & 3,3 & 4,3 & 5,6 & 1,5 \\
1989 & 3,6 & 4,6 & 5,8 & 1,3 \\
1990 & 3,0 & 3,7 & 4,4 & 1,2 \\
1992 & 2,8 & 3,6 & 4,7 & 1,5 \\
1993 & 2,9 & 3,7 & 6,2 & 1,8 \\
1995 & 3,6 & 4,4 & & \\
\hline
\end{tabular}

Fonte: PNAD/95 — IBGE

Inclui as pessoas empregadas com 10 anos de idade ou mais no Brasil, à exceção da área rural da Região Norte.

Tabela 16: Índices da remuneração média real dos servidores e da evolução das despesas com pessoal do Executivo

\begin{tabular}{lccc}
\hline & $\begin{array}{c}\text { Índice de remun. } \\
\text { PCC-nível superior }\end{array}$ & $\begin{array}{c}\text { Índice de remun. } \\
\text { ponderado } *\end{array}$ & $\begin{array}{c}\text { Índice de evolução } \\
\text { das despesas }\end{array}$ \\
\hline 1989 & 100 & 100 & 100 \\
1990 & 106 & 110 & 113 \\
1991 & 70 & 73 & 92 \\
1992 & 62 & 65 & 75 \\
1993 & 82 & 82 & 101 \\
1994 & 99 & 100 & 117 \\
1995 & 117 & 128 & 153 \\
1996 & 101 & 111 & 147 \\
\hline
\end{tabular}

Fonte: Boletim Estatístico do MARE.

(1) Os índices de remuneração incluem os servidores civis do Poder Executivo (adm. direta, autarquias e fundações), e correspondem às médias anuais; o da evolução das despesas reflete o gasto acumulado no ano para todo o Executivo federal (inclui civis e militares).

* Com base nas seguintes carreiras: procurador da Fazenda, auditor fiscal, analista de finanças e controle, gestor, analista de orçamento, diplomata e os cargos do PCC (nível superior, intermediário e auxiliar).

Esta aparente eqüidade embute, entretanto, um grave problema: a hierarquia salarial não obedece a relevância de responsabilidades e atribuições, implicando um claro desestímulo para as pessoas mais qualificadas ingressarem no serviço público, assim como para os próprios servidores na busca de sua capacitação e progressão profissional. Logo, uma política salarial eficaz deveria envolver, necessariamente, correções setoriais a fim de sanar estas distorções. 
A atual estrutura remuneratória influi no sentido contrário às necessidades do governo federal, uma vez que este último necessita recrutar trabalhadores mais qualificados. Poder-se-ia contra-argumentar que a maioria dos servidores existentes possuem escolaridade de nível superior e, portanto, a estrutura salarial não estaria atuando no sentido inverso ao desejado. Mas é justamente neste aspecto que reside a contradição; como o salário médio dos cargos que exigem escolaridade de $2^{\circ}$ grau é relativamente mais elevado, porque o salário dos cargos que exigem escolaridades de $2^{\circ}$ grau é mais próximo no setor público e no privado que para os cargos executivos e aqueles que exigem escolaridade de nível superior. Muitas pessoas que ingressaram nestas posições possuem nível superior (e este é um dos fatores decisivos para o descompasso entre escolaridade e perfil dos cargos ocupados), enquanto os cargos que exigem escolaridade de nível superior para o seu desempenho, para os quais o governo está direcionando sua política de contratações, são menos atrativos, pois o salário, que constitui uma informação relevante para a decisão de ingresso, é comparativamente menor para tais posições.

Tabela 17: Comparação salarial entre o setor público e privado Valores atualizados pela inflação até maio/1995.

\begin{tabular}{lccc}
\hline Cargos & $\begin{array}{l}\text { Salário médio } \\
\text { S. Privado }\end{array}$ & $\begin{array}{l}\text { Salário médio } \\
\text { S. Público }\end{array}$ & $\begin{array}{c}\text { Diferença } \\
\text { Públ./Priv. }\end{array}$ \\
\hline Executivos & 7.080 & 6.069 & $-14 \%$ \\
Nível superior & 1.899 & 1.814 & $-5 \%$ \\
Nível técnico/médio & 926 & 899 & $-3 \%$ \\
Operacionais & 437 & 635 & $45 \%$ \\
\hline
\end{tabular}

Fonte: SIAPE/MARE e Coopers \& Lybrand.

Metodologia de cálculo:

Inicialmente, foram levantados os cargos com atribuições semelhantes no setor público (civis do Executivo) e no privado. Para calcular a remuneração média de cada cargo, foi utilizado, no setor privado, o salário médio, independentemente do porte e da localidade das empresas, para o setor público, foi considerada a estrutura de remuneração e a distribuição de frequiência dos servidores na escala salarial de cada cargo. Para os cargos de nível executivo, foi levantada uma amostra do valor da remuneração dos ocupantes de DAS de diversos níveis, considerando o diretor-presidente como DAS de natureza especial, diretores como DAS-6 e gerentes como DAS-5, exceto para os cargos da área jurídica, que têm uma estrutura hierárquica um pouco distinta. Não estão incluídos benefícios indiretos dos cargos.

Existe uma outra grave distorção na estrutura remuneratória do serviço público associada às sentenças judiciais, notadamente aquelas relativas ao pagamento de planos econômicos que o próprio Supremo já julgou inconstitucional. Apesar da União estar recorrendo das decisões de juízes das primeiras instâncias, e estar sendo bem-sucedida, existem muitas sentenças antigas já transitadas em julgado que permitem a um servidor ganhar acima de seu colega que possui o mesmo cargo e desempenha as mesmas atribuições. ${ }^{12}$ 
Exemplificando, o salário de um ocupante de um típico cargo de nível médio, cujo valor máximo sem adicionais atinge $R \$ 806$, pode ser elevado para $\mathrm{R} \$ 1.485$ se o indivíduo obtiver na justiça o direito de ter seus vencimento corrigidos pela inflação de março de 1990 (84,32\%, que incorpora um grande resíduo pós-Plano Collor), o que o deixaria numa situação muito confortável até mesmo diante dos seus colegas que exercem um cargo básico de nível superior cuja remuneração máxima (também sem adicionais) chega a $\mathrm{R} \$ 1.363$. Note-se que em todos os órgãos onde a participação das despesas com sentenças no total da folha é significativa, o salário médio é superior à média geral, e a maior parte destes órgãos são escolas ou universidades.

A análise detalhada dos dados relativos à estrutura remuneratória do serviço público indica, ao contrário das impressões iniciais, que o salário dos servidores é inadequado. Isto ocorre porque a sua remuneração não é compatível com a obtida no mercado privado, a escala salarial não corresponde à hierarquia de atribuições e até mesmo pessoas ocupando cargos semelhantes, com atribuições idem, recebem salários distintos devido a uma decisão judicial muitas vezes infundada. Como resultado a escala remuneratória, que deve considerar fatores como as atribuições do cargo, a qualificação e o desempenho do servidor, torna-se sensivelmente prejudicada.

Tabela 18: Relação entre gastos com sentenças e salário médio dos órgãos do Poder Executivo federal

\begin{tabular}{lrc}
\hline Órgão & $\begin{array}{c}\text { Sentenças/ } \\
\text { Folha (1) }\end{array}$ & $\begin{array}{c}\text { Salário } \\
\text { Médio (2) }\end{array}$ \\
\hline Polícia Federal & $57,9 \%$ & 3.950 \\
Escola Superior Agrícola de Mossoró & $40,5 \%$ & 2.124 \\
Escola Técnica Federal do Rio Grande do Norte & $29,8 \%$ & 1.594 \\
Universidade Federal de Rondônia & $27,7 \%$ & 1.526 \\
Escola Técnica Federal de Alagoas & $22,6 \%$ & 1.373 \\
Universidade Federal do Rio de Janeiro & $21,5 \%$ & 1.503 \\
Universidade do Maranhão & $21,2 \%$ & 1.617 \\
Faculdade de Medicina do Triângulo Mineiro & $19,8 \%$ & 1.323 \\
Universidade do Rio Grande & $18,0 \%$ & 1.933 \\
Escola Técnica Federal de Campos & $17,3 \%$ & 1.353 \\
Universidade Federal de Alagoas & $16,2 \%$ & 1.505 \\
Universidade Federal de Santa Catarina & $15,8 \%$ & 1.704 \\
Outros & $3,4 \%$ & 1.266 \\
\hline Total Folha & $6,0 \%$ & 1.300 \\
\hline
\end{tabular}

Fonte: SIAPE / Secretaria de Recursos Humanos do MARE.

(1) Corresponde à participação dos gastos com sentenças na folha de pagamento dos diversos órgãos no período janjun/1996.

(2) Salário médio dos servidores dos órgãos, posição de julho/1996. 
A crise fiscal influiu consideravelmente nas condições do mercado de trabalho nos últimos anos, principalmente no tocante ao nível de emprego e, mais recentemente, no que concerne à evolução dos salários, mas a rigidez da legislação atual de recursos humanos parece ser o fator determinante das distorções apontadas ao longo do texto, que geram uma forte segmentação entre o mercado de trabalho público e o privado. Neste sentido, a aprovação das reformas administrativa e previdenciária, que reduzirão custos e introduzirão flexibilidade e racionalidade, são fundamentais para que a política de recursos humanos possa ser administrada com um maior grau de liberdade no setor público.

O gasto do governo com pessoal é excessivo e de má qualidade, pois as alterações da escala salarial nos últimos anos foram determinadas por concessões administrativas e decisões judiciais, fatores estes totalmente adversos às atribuições desempenhadas, à capacitação e ao mérito, que são extremamente relevantes para a administração salarial em qualquer área. Por sua vez, uma estrutura de cargos estanque, especializada e concentrada nas atividades de apoio, é incompatível com o planejamento adequado do quadro de pessoal e com o processo de modernização do Estado.

A gestão de recursos humanos deve direcionar os seus esforços para corrigir as atuais distorções salariais inibidoras do desenvolvimento profissional dos indivíduos; flexibilizar o atual sistema de cargos e carreiras; introduzir formas adequadas de estímulo à capacitação; e concentrar o recrutamento de pessoal nas áreas finalísticas que se encontram desfortalecidas. Em suma, é fundamental transformar o atual perfil do servidor público, dotando-o de características eminentemente gerenciais, a fim de que o mesmo possa se adequar e contribuir decisivamente para a reforma da administração pública brasileira em curso. 
1 A exemplo da administração pública global, o emprego no mercado de trabalho privado também evoluiu positivamente no período considerado, pois, ainda que o dado referente ao mercado de trabalho global inclua o setor público e o privado, a participação deste último na informação agregada é bem maior e, portanto, decisiva para a definição do comportamento do emprego no conjunto da economia.

2 Até outubro de 1996, as pessoas que se aposentavam com direito a receber vencimentos integrais obtinham uma promoção no ato do afastamento, que elevava os seus rendimentos, em média, em $8,3 \%$.

3 Os dados cadastrais demonstram que $42 \%$ dos servidores possuem curso superior. Como esta informação pode estar subestimada, uma vez que não é atualizada periodicamente, e apenas $34 \%$ do total de cargos ocupados requerem formação de nível superior para o seu desempenho, torna-se evidente a inconsistência entre o grau de escolaridade dos servidores e o perfil dos cargos ocupados atualmente. A adequação entre estas duas variáveis deverá ocorrer a médio prazo, com a realização periódica de concursos públicos de acordo com o planejamento da força de trabalho, uma vez que a ascensão funcional foi proibida porque vinha sendo utilizada de forma irregular.

$4 \mathrm{Na}$ França, por exemplo, existem poucas áreas (Diplomacia e Tribunal de Contas são dois casos) nas quais as carreiras são específicas.

5 Esta estratégia parece estar associada a economias em que o Estado encontrase em crise fiscal. Um indício desta correlação é a existência de estrutura semelhante em outros países da América Latina.

6

O motivador da reduzida amplitude salarial na administração estadual e municipal não foi pesquisado. Entretanto, uma vez que seus governos tendem a seguir as diretrizes adotadas em nível federal, é muito provável que a dinâmica das gratificações também seja responsável por este comportamento.

7 Ver tabela 16. Um reajuste implica o aumento da remuneração de ativos, inativos e pensionistas, irradiando-se, portanto, por toda a folha de pagamento. Existem outros fatores que também explicam as variações na despesa de pessoal, como as contratações, as promoções, as incorporações de vantagens e a passagem para a inatividade (sendo que alguns destes já foram eliminados), mas os reajustes correspondem ao principal fator de pressão, pois, via de regra, resultam num impacto maior que os demais. Prova disto é que as variações da folha e dos salários não são exatamente iguais, mas ocorrem sempre no mesmo sentido.

8 Carta de Conjuntura do Ipea, n.62, fev/96.

9 Aqui também vale o raciocínio desenvolvido no início do texto. Ainda que o dado utilizado refira-se ao conjunto dos trabalhadores (aí incluídos os próprios servidores), é possível considerar que o seu comportamento é definido primordialmente pelos empregados do setor privado, que constituem a ampla maioria da força de trabalho do País. Conseqüentemente, esta informação pode ser utilizada como uma proxy das características da distribuição da renda no mercado de trabalho privado.

10 Certamente existem alguns cargos específicos do setor público, dadas algumas competências exclusivas deste último. Casos típicos desta situação são os fiscais e os policiais. Existe, porém, uma quantidade muito maior de cargos que possuem atribuições próximas nos dois mercados de trabalho, cujas 
remunerações podem ser facilmente comparadas. Mesmo para os cargos que possuem atribuições tidas como específicas do setor público, a comparação entre remunerações médias dos postos que exigem o mesmo nível de escolaridade (ou qualificação) nos dois mercados é relevante para a decisão de ingresso nestas carreiras.

11 Esta situação é fruto, por um lado, de uma série de promoções generalizadas para os ocupantes de cargos operacionais ocorridas até meados da década e, por outro lado, de uma forte restrição a aumentos para os cargos de nível superior integrantes de planos de carreira mais amplos ou de categorias mais populosas, com salários superiores aos dos ocupantes de cargos operacionais, que pudessem implicar um impacto considerável sobre as despesas com pessoal.

12 Enquanto a distorção analisada inicialmente surge da comparação entre salários nos dois setores, esta última decorre da comparação entre salários recebidos por ocupantes do mesmo cargo, constituindo-se um desestímulo à busca de qualificação tão intenso quanto o decorrente da primeira.

\section{Referências bibliográficas}

BLANK, Rebecca M. - ““An Analysis of workers' choice between employment in the public and private sectors", In: Industrial and labor relations review, v.38, n.2, 1985.

Brasil, Presidente, 1995. Plano diretor da reforma do Estado. Brasília: Presidência da República/MARE, 1995.

Bresser Pereira, L. C. - Da administração pública burocrática à gerencial. (mimeo), 1996.

Bresser Pereira, L.C., Przeworski, A., Maravall, J.M. - Economic reforms in new democracies; A social-democratic approach. Canadá: Cambridge University, 1993.

CaVAlieri, Cláudia H. e Fernandes, Reynaldo. Diferenciais de salário por gênero e cor: uma comparação entre as regiões metropolitanas brasileiras. In: Encontro Nacional de Economia, 23, 1995, Salvador. Anais... Salvador:1995.

Ehrenberg, Ronald G. e Schwarz, Joshua L. Public sector labor economics. In: Ashenfelter, O., LAYARD, R., Handbook of labor economics, v.II. (NorthHoland): Elsevier, 1986.

Ehrenberg, Ronald G. e SMith, Robert S. - Modern labor economics. New York: Harper Collins College Publishers, 1994, 5.ed.

Freeman, Richard B. How do public sector wages and employment respond to economic conditions? In: Wise, David A. (ed.), Public sector payrolls. Chicago University, 1987.

Hewitt, Daniel, V An Rijckeghem, Caroline. Wage expenditures of central governments. (s.1.): (s.n.), 1995.

IBGE. Pesquisa nacional por amostragem de domicílio — 1993. Rio de Janeiro: 1995.

MACEDo, Roberto. Os salários nas empresas estatais. São Paulo/Brasília: Nobel/ Ministério do Trabalho, 1985. 
Marconi, Nelson. O comportamento dos salários reais em uma conjuntura inflacionária. São Paulo: Fundação Getúlio Vargas, 1993. (Dissertação de mestrado).

Martins, Luciano. Estatização da economia ou privatização do Estado. Ensaios de opinião, v.2, n.7. 1978.

Mercado de trabalho - Conjuntura e análise. Rio de Janeiro: Ipea, 1996.

NunBerg, Barbara. Experience with civil service pay and employment reform: an overview. In: Lindauer, David L., Nunberg, Barbara (ed.). Rehabiliting government; pay and employment reform in Africa. Washington: World Bank, 1994.

Pedersen, P.J. et al. Wage differentials between the public and private sector. Journal of public economics, n.41, 1990.

Saldanha, R., Maia, R., CAmargo, J.M. Emprego e salário no setor público federal. Brasília: Ministério do Trabalho, 1988 (Texto para discussão, n.5).

SAntos, Sérgio Cutolo. Política de recursos humanos e reforma do Estado. (s.1.): (s.n.), 1994. (mimeo).

Taubman, Paul, Wachter, Michael L. Segmented labor markets. In: Ashenfelter, O., LAYARD, R., Handbook of labor economics, v.2. (North-Holand): Elsevier, 1986.

Urani, André, Ramalho, Mariana. A administração pública como empregadora: uma avaliação da década de 80. Rio de Janeiro: Ipea, 1995. (Série seminários, n.5).

Venti, Steven F. Wages in the federal and private sectors. In: Wise, David A. (ed.). Public sector payrolls. Chicago: Chicago University, 1987.

WORLD BANK. World development report 1995. Washington: 1996. 


\section{Resumo \\ Resúmen \\ Abstract}

\section{Uma breve comparação entre os mercados de trabalho do setor público e privado}

Nelson Marconi

Este artigo apresenta diversas características dos mercados de trabalho do setor público e privado, ressaltando as disparidades entre ambos e, mais especificamente, as distorções observadas no setor público, a fim de demonstrar o grau de segmentação entre ambos. As comparações se dão em torno do comportamento do emprego, do perfil dos trabalhadores e da dinâmica das remunerações. A análise evidencia que a crise fiscal e a rigidez da legislação são determinantes fundamentais das características e distorções (e conseqüentemente da segmentação) observadas no setor público e que a flexibilização das regras atuais, assim como as reformas constitucionais em curso, constituem importante condição para a aproximação entre os dois mercados e a melhoria da gestão de recursos humanos na administração pública.

\section{Una breve comparación entre los mercados de trabajo del sector público y privado}

\section{Nelson Marconi}

Este artículo presenta diversas características de los mercados de trabajo del sector público y privado, destacando las disparidades entre ambos y, más específicamente, las distorsiones observadas en el sector público, con el objeto de demostrar el grado de segmentación entre ambos. Las comparaciones se dan alrededor del comportamiento del empleo, del perfil de los trabajadores y de la dinámica de las remuneraciones. El análisis evidencia que la crisis fiscal y la rigidez de la legislación son factores determinantes fundamentales de las características y distorsiones (y, en consecuencia, de la segmentación) observadas en el sector público, y que la flexibilización de las reglas actuales, así como las reformas constitucionales que están en marcha, constituyen una importante condición para el acercamiento entre los dos mercados y la mejora de la gestión de los recursos humanos de la administración pública.

\section{A brief comparison between the public and private sectors labor markets \\ Nelson Marconi}

The article presents several aspects of the public and private sectors labor markets, stressing the disparities among both and, more specifically, the distortions noticed in the public sector, with a view to demonstrate the level of segmentation between them. Comparisons are made in respect of job behavior, worker's profile and waging mechanisms. The analysis evidences that both the taxation crisis and the legal stiffness are basic determinants of the characteristics and distortions (and consequently of the segmentation) observed in the public sector, and that the increasing flexibility of the present rules, as well as the on going constitucional reforms, constitute an important condition for bringing the two markets closer and improving human resources management within the public administration.
Revista do

Serviço

Público

Ano 48

Número 1

Jan-Mar 1997

\author{
Nelson \\ Marconi é \\ mestre e \\ doutorando \\ em economia \\ pela FGV/SP e \\ diretor do \\ Departamento \\ de Carreiras e \\ Remuneração \\ da Secretaria \\ de Recursos \\ Humanos do \\ MARE
}

